\title{
Paper
}

Practica oto-rhino-laryngologica 1945;7:262

\section{Oesophagoplastie préthoracique cutanée}

M.

Rapin

Yverdon

Rapport pas $\gamma \theta$ çu.

Incisions et sutures esthétiques en O.R.L.

Par M. RAPIN (Yverdon). Rapport pas reçu.

Kiefcrosteomyelitis beim Säugling und Kleinkind.

Von A. RODEL (Olten).

Erscheint später ausführlich in dieser Zeitschrift. 